\title{
Notes on topological rings
}

\section{MiHAIL URSUl and MARTIN JUŔAš}

\section{ABSTRACT.}

We prove that every infinite nilpotent ring $R$ admits a ring topology $\mathcal{T}$ for which $(R, \mathcal{T})$ has an open totally bounded countable subring with trivial multiplication. A new example of a compact ring $R$ for which $R^{2}$ is not closed, is given. We prove that every compact Bezout domain is a principal ideal domain.

\section{Acknowledgements. Dedicated to the memory of Krasarm Konstantinovici Schiukin.}

\section{REFERENCES}

[1] Arnautov, V., Glavatsky, S. and Mikhalev, A., Introduction to the theory of topological rings and modules, Marcel Dekker, Inc, 1996

[2] Choban, M. and Ursul, M., Applications of the Stone duality in the theory of precompact Boolean rings, Advances in ring theory, 85-111, Trends Math., Birkhäuser, Springer, Basel AG, Basel, 2010

[3] Dikranjan, D. and Shakhmatov, D., The Markov-Zariski topology of an abelian group, J. Algebra, 324 (2010), No. 6, 1125-1158

[4] Engelking, R. and Pełczynski, A., Remarks on dyadic spaces, Coll. Math., 11 (1963), 55-63

[5] Hartman, S. and Mycielski, J., On the imbedding of topological groups into connected topological groups, Colloq. Math., 5 (1958), 167-169

[6] Hesse, G., Zur Topologisierbarkeit von Gruppen (Univ. Hannover, Hannover, 1979)

[7] Koppelberg, S., Handbook of boolean algebras, (Monk, J. Donald and R. Bonnet, Eds.), vol. 1, Elsevier Science Publishers, 1989

[8] Kertesz, A. and Szele, T., On the existence of non-discrete topologies in infinite abelian groups, Publ. Math. Debrecen, 3 (1953), 187-189

[9] Lanski, C., Rings with few nilpotents, Houston J. Math., 18 (1992), No. 4, 577-590

[10] Malcev, A. I., Topological algebra and Lie groups, In Mathematics in USSR, 1917-1947 (A. G. Kurosh, A. I. Markushevici and P. K. Rashevski, Eds.) Moscow-Leningrad, 1948, 134-180

[11] Ol'shanskii, A. Yu., A note on countable non-topologizable groups, Vestnik Mosk. Gos. Univ. Mat. Mekh., 103 (1980), No. 3

[12] Shelah, S., On a problem of Kurosh, Jonsson groups and applications, in Word Problems II (S. I. Adian, W. W. Boone and, G. Higman, Eds.), North-Holland, Amsterdam, 1980, 373-394

[13] Sikorski, R., Boolean Algebras, Third edition, Berlin-Göttingen-Heidelberg-New York, 1969

[14] Ursul, M., Topological Rings Satisfying Compactness Conditions, Vol. 549, Kluwer Academic Publishers, Dordrecht-Boston-London, 2002

[15] Witt, E., Über die kommutatorgruppe kompakter Gruppen, Rend. Math. e Appl., 14 (1954), 627-630

\author{
DePARTMENT OF MATHEMATicS AND COMPUTER SCIENCE \\ PNG UNIVERSITY OF TECHNOLOGY \\ Private Mail Bag Lae 411, Lae, Papua New Guinea \\ E-mail address: mursulecms.unitech.ac.pg \\ E-mail address: mihail.ursulegmail.com
}

Received: 25.10.2011; In revised form: 03.07.2012; Accepted: 14.09.2012

2010 Mathematics Subject Classification. 16W80.

Key words and phrases. Nilpotent ring, commutator ideal, countably compact ring, $\sigma$-complete boolean ring, projective boolean ring, Bezout domain.

Corresponding author: Mihail Ursul; mihail.ursul@gmail.com 
Department of Mathematics and Physics

QATAR UNIVERSITY

P.O. BOX 2713, DOHA, QATAR

E-mail address: martinequ. edu.qa 